\title{
Organic groups influencing microporosity in organosilicas
}

\author{
A. Petra Dral, Johan E. ten Elshof* \\ MESA+ Institute for Nanotechnology, University of Twente, P.O. Box 217, 7500 AE Enschede, The \\ Netherlands
}

\begin{abstract}
The micropore structure of a series of organosilica materials with various organic groups in bridging (methylene, ethylene, hexylene, octylene, $p$-phenylene) and terminal (methyl, $n$-propyl) positions was analyzed and compared to that of inorganic amorphous silica. Vapor thermogravimetry with water, methanol, 1-propanol and cyclohexane vapors was used to measure accessible pore volumes, pore entrance sizes and surface chemistries. Gas pycnometry with $\mathrm{He}, \mathrm{Ar}$ and $\mathrm{N}_{2}$ was used to measure skeletal densities, semi-quantitative surface-to-volume ratios and surface areas, pore entrance sizes and semi-quantitative pore cavity sizes. Conventional adsorption isotherms were measured for $\mathrm{N}_{2}$ at $-196{ }^{\circ} \mathrm{C}$ to check for mesoporosity and for $\mathrm{CO}_{2}$ at 0 ${ }^{\circ} \mathrm{C}$ to obtain Brunauer-Emmett-Teller surface areas for comparison. The known classification of 1) short or rigid organic bridges that open up the pore structure, 2) longer and more flexible bridges that cause pore filling and 3) terminal organic groups that reduce pore formation is further specified. The incorporation of any organic group in the silica network increased the dispersity in micropore entrance sizes as compared to inorganic silica in the probed size range. A critical discussion is given of the commonly accepted 'spacing concept' of organic bridges.

Keywords: organosilica, microporosity, analysis, adsorption, pycnometry, thermogravimetry
\end{abstract}




\section{Introduction}

The incorporation of organic groups in amorphous silica networks, i.e. replacement of Si-O-Si linkages with Si-R or Si-R-Si linkages, influences various functional properties such as mechanical flexibility and fracture resistance [1,2], hydrophobicity [3-5] and hydrothermal stability [5-8]. For applications that make use of the microporosity of organosilica materials, such as separation membranes, varying the nature and location of the organic groups allows tuning of micropore sizes and surface chemistries. Organic groups in bridging position (Si-R-Si) are part of the network backbone and act as spacers when they are short or rigid such as methylene $\left(-\mathrm{CH}_{2}-\right)$, ethylene $\left(-\mathrm{C}_{2} \mathrm{H}_{4}-\right)$, ethenylene $\left(-\mathrm{C}_{2} \mathrm{H}_{2-}\right)$ and phenylene $\left(-\mathrm{C}_{6} \mathrm{H}_{4}-\right)$ groups [9-15]. Though methylene-bridged silica networks have only single-atom spacers between neighboring Si atoms, similar to inorganic silica, the network opens up because Si-C bonds (1.97 $\AA$ ) are longer than Si-O bonds (1.57-1.59 $\AA$ ) [16]. Si-C-Si bonds are also more rigid because they do not have the impressive freedom of over $40^{\circ}$ variation in bond angle that Si-O-Si bonds have [17]. Long and flexible bridges such as hexylene $\left(-\mathrm{C}_{6} \mathrm{H}_{12^{-}}\right)$and octylene $\left(-\mathrm{C}_{8} \mathrm{H}_{16^{-}}\right)$groups tend to collapse and fill up the empty space $[12,13,18-20]$. The bulkiness of these bridges is still sufficiently low to allow high network condensation degrees [5], but they transform the network towards a flexible polymer-like structure through which molecules can pass based on affinity rather than through pre-existing pore channels $[12,20]$. Membrane permeation data have shown that the effective pore entrance size generally increases for bridges in the order $\mathrm{O}$ (inorganic silica) $<\mathrm{CH}_{2}<\mathrm{C}_{2} \mathrm{H}_{4}<\mathrm{C}_{3} \mathrm{H}_{6}<\mathrm{C}_{6} \mathrm{H}_{12}<\mathrm{C}_{8} \mathrm{H}_{16}$ and $\mathrm{C}_{2} \mathrm{H}_{4}<p-\mathrm{C}_{6} \mathrm{H}_{4}$ $<\mathrm{C}_{8} \mathrm{H}_{16}[9,12,20,21]$. If organic groups are placed in terminal position (Si-R), they do not act as spacers between adjacent Si atoms and easily fill up the pores created by the silica backbone. However, terminal methyl $\left(-\mathrm{CH}_{3}\right)$ and phenyl $\left(-\mathrm{C}_{6} \mathrm{H}_{5}\right)$ groups have also been reported to increase the effective pore opening size in membrane applications as compared to inorganic silica [22] and 
methyl groups can increase the total pore volume [3]. Organic groups in terminal position increase the network hydrophobicity by sticking out at the pore surface $[3,4,22,23]$.

Although the incorporation of short or rigid organic bridges between Si atoms clearly increases the size of part of the micropore entrances and/or cavities, this 'spacing concept' requires a closer look. Firstly, the effect of organic bridges acting as spacers between Si atoms tends to be generalized to the expansion of all micropores. However, it should be kept in mind that about $75 \%$ of the bridging units still remains the same (Si-O-Si) as in inorganic silica networks when using trialkoxysilyl precursors. The formation of small rings with only Si-O-Si linkages is still possible. Molecular dynamics simulation studies on inorganic and ethylene-bridged silica networks predict a reduction of the number of smallest pores but not their disappearance [11,24], though the random distribution of ethylene bridges in these models differs from reality. The generally observed superiority of inorganic silica membranes in terms of reaching the highest permeation selectivities for very small molecules such as $\mathrm{H}_{2} \mathrm{O}$ and $\mathrm{H}_{2}$ is thus not self-evident.

Secondly, the pore size expansion in organically bridged networks that is achieved in reality, does not only result from the bridges acting as spacers between $\mathrm{Si}$ atoms but also results from altered kinetics during network compaction in sol-gel processing. The incorporation of organic bridges changes the size, shape, flexibility and connectivity of the monomer unit. These properties affect the monomer mobility during drying and consolidation of the material after synthesis. For example, methylene- and ethylene-bridged silica monomers are about twice as large as inorganic silica monomers, have six connection points to the surrounding network instead of four and have a linear shape instead of spherical. This yields a lower monomer mobility during compaction, which in turn increases the number of pores that are kinetically trapped at larger sizes and also different shapes than preferred thermodynamically. Some experimental results on 
these effects can be found in a consolidation study previously reported by us [25]. Elaborate data sets of entire micropore structures in organosilica materials to further evaluate these issues are scarce. Commonly used membrane permeation measurements mainly probe the bottlenecks along permeation pathways and cryogenic adsorption ( $\left.N_{2}, A r\right)$ excludes the smallest micropores due to diffusion limitations.

In the present study, in-depth comparative data on the microporous networks of a range of organosilica materials is obtained via our recently reported method of vapor thermogravimetry (TG) and gas pycnometry (PM) [26]. This method uses a range of solvents and non-polar gases to probe micropore volumes, sizes and surfaces at room temperature. (Organo)silica materials were prepared from the precursors listed in Figure 1 by sol-gel processing. The presence of mesoporosity was analyzed with conventional $\mathrm{N}_{2}$ adsorption isotherms at $-196^{\circ} \mathrm{C}$. Vapor $\mathrm{TG}$ was used to measure accessible pore volumes, pore entrance sizes and surface chemistries. Gas PM was used to measure skeletal densities, semi-quantitative surface-to-volume ratios and surface areas, pore entrance sizes and semi-quantitative pore cavity sizes. Water, methanol, 1-propanol and cyclohexane were used as vapor probe molecules for TG. He, Ar and $\mathrm{N}_{2}$ were used as gas probe molecules for PM. The above discussed classification of 1) short or rigid organic bridges that open up the pore structure, 2) longer and more flexible bridges that cause pore filling and 3) terminal organic groups that reduce pore formation is used as framework for the discussion and is further specified. A relation between the incorporation of organic groups and the dispersity in pore entrance sizes is presented. 


\section{Experimental}

\subsection{Chemicals}

Bis(triethoxysilyl)methane (97\% purity), 1,2-bis(triethoxysilyl)ethane (97\% purity), 1,6-

bis(trimethoxysilyl)hexane (97\% purity), 1,8-bis(triethoxysilyl)octane (97\% purity), 1,4-

bis(triethoxysilyl)benzene (95\% purity), 1,2-bis(methyldiethoxysilyl)ethane (purity unknown), methyltrimethoxysilane ( $97 \%$ purity), $n$-propyltrimethoxysilane ( $98 \%$ purity) and tetraethoxysilane (99\% purity) were obtained from ABCR. Nitric acid was obtained from Sigma Aldrich (70 wt\% aqueous solution) and Acros (65 wt\% aqueous solution). Anhydrous ethanol (purity $99.8 \%,<0.01 \%$ $\mathrm{H}_{2} \mathrm{O}$ ) was obtained from VWR and SeccoSolv. Anhydrous methanol (purity $99.8 \%,<0.005 \% \mathrm{H}_{2} \mathrm{O}$ ) was obtained from VWR. Anhydrous 1-propanol (purity 99.9\%) and cyclohexane (purity >99\%) were obtained from Alfa Aesar.

\subsection{Sample preparation}

(Organo)silica materials were synthesized as reported elsewhere [5]. The $\mathrm{HNO}_{3}: \mathrm{H}_{2} \mathrm{O}$ : alkoxy ratio was $0.064: 1.1: 1.0$, as derived from Castricum et al. [12]. The resulting materials were ground to powder by ball milling and were consolidated at $300{ }^{\circ} \mathrm{C}$ in $\mathrm{N}_{2}$ for $3 \mathrm{~h}$. All samples were stored under ambient conditions.

\subsection{Thermogravimetry}

Thermogravimetric data was recorded as reported elsewhere [26]. In short, the sample was dried at $200{ }^{\circ} \mathrm{C}$ in synthetic air $\left(\mathrm{N}_{2}: \mathrm{O}_{2} 80: 20\right)$ for $4 \mathrm{~h}$, stabilized at $30^{\circ} \mathrm{C}$ in synthetic air for $1 \mathrm{~h}$, filled with vapor at $30{ }^{\circ} \mathrm{C}$ in humidified $\mathrm{N}_{2}$ for $18 \mathrm{~h}$, flushed at $30^{\circ} \mathrm{C}$ in synthetic air for $1 \mathrm{~h}$ and dried at $200{ }^{\circ} \mathrm{C}$ 
in synthetic air for $4 \mathrm{~h}$. The supplied gases were dried with SGE packed column moisture traps and the $\mathrm{N}_{2}$ was subsequently humidified by bubbling through a solvent at room temperature.

\subsection{Pycnometry}

Pycnometry measurements were done as reported elsewhere [26]. In short, the sample was loaded in the sample cell and dried in an oven at $150^{\circ} \mathrm{C}$ under $\mathrm{N}_{2}$ flow for $3 \mathrm{~h}$. Immediately afterwards, the sample was weighed and loaded in the pycnometer. The apparent sample volume was analyzed at room temperature with single-gas and two-gas measurements in the order $\mathrm{He}$, $\mathrm{He}+\mathrm{He}, \mathrm{He}+\mathrm{N}_{2}, \mathrm{Ar}, \mathrm{N}_{2}$ and $\mathrm{N}_{2}+\mathrm{N}_{2}$. The measurement series started with He because of its smallest size and lowest adsorption, which facilitates removal of atmospheric residues from the pores prior to data collection.

\subsection{Adsorption isotherms}

Adsorption isotherms were collected with a Quantachrome Instruments Autosorb-1 and the gases were led through a moisture trap before entering the set-up. The sample was outgassed at $300{ }^{\circ} \mathrm{C}$ for $3 \mathrm{~h}$. Adsorption isotherms were collected for $\mathrm{CO}_{2}$ at $0{ }^{\circ} \mathrm{C}$ and for $\mathrm{N}_{2}$ at $-196{ }^{\circ} \mathrm{C}$. BrunauerEmmett-Teller (BET) curves derived from $\mathrm{CO}_{2}$ adsorption were based on at least 4 data points.

\section{Results and discussion}

\subsection{Mesoporosity}

Isothermal adsorption and desorption curves of $\mathrm{N}_{2}$ at $-196^{\circ} \mathrm{C}$ were recorded for the (organo)silica materials to determine whether the networks contained mesopores. Results are shown in Figure 2. The curves for BTESM-, BTESE-, BTESB-, BTMSH- and MTMS-derived networks correspond to microporous type I isotherms of the IUPAC classification and indicate no significant mesoporosity. 
The observed hysteresis over the entire pressure range may be related to slow penetration of $\mathrm{N}_{2}$ in very narrow cavities or packing transitions. TEOS- and BTESO-derived materials yielded a combination of type I and type IV isotherms, indicating that these pore structures contained micropores and mesopores. Hardly any porosity was measured for PTMS-derived networks. BMDESE-derived material could not be outgassed sufficiently to obtain adsorption data.

\subsection{Pore volume, entrance size and surface chemistry}

Vapor TG measurements were done to determine the uptake of water, methanol, 1-propanol and cyclohexane in the (organo)silica networks. The mass uptake was divided by the bulk liquid density to estimate the uptake in terms of volume, though the solvents do not necessarily maintain their bulk densities inside the micropores due to the small micropore sizes and significant wall-solvent interactions. The volume uptake of methanol was taken as the accessible pore volume $V_{\text {acc }}$. The

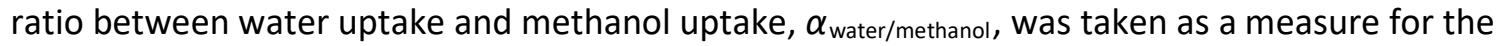
pore hydrophobicity. Gas PM measurements were done with He to obtain the He density $\rho_{\mathrm{He}}$ and calculate the porosity $\Phi$. Results are shown in Figure 3 and Table 1. Interparticle adsorption of any solvent was not observed in our previously reported analysis of a series of zeolites [26] and was thus not expected for the (organo)silicas either. Attempts to characterize the micropores further by measuring the vapor uptake at various partial pressures yielded insufficient accuracy. Recalculation of the PM results with calibration shifts as observed throughout the measurements and with duplicate measurements yielded only minor deviations (within 1 digit or 5\%).

The obtained pore volumes roughly correspond with the classification of materials based on spacer type as discussed in the introduction. The short and rigid spacers in BTESM-, BTESE- and BTESB-derived materials increased the pore volume per Si atom as compared to TEOS-derived 
material. However, the more rigid and longer phenylene bridges in BTESB-derived material as compared to ethylene bridges in BTESE-derived material did not cause an increase in empty volume; the total porosity was smaller in BTESB-derived material and the accessible volumes per Si atom were similar. This suggests that some phenylene rings aligned due to $\pi-\pi$ stacking, counteracting their spacing effect. In BTMSH- and BTESO-derived material the bridges are too long and flexible to increase the pore volume as compared to inorganic silica and indeed yielded a lower porosity that decreased with increasing bridge length. The terminal organic groups in MTMS- and PTMS-derived material do not expand the network backbone and can increase the packing density as compared to inorganic silica, corresponding with the observed smaller pore volumes. However, the significantly lower He densities of MTMS- and PTMS- as compared to BTESE- and BTMSH-derived networks indicate that the first ones contained larger pore fractions that are inaccessible to He (pores inaccessible to He suppress the measured He density). This has also been reported for methylated silica elsewhere [3]. The He sample volumes per Si atom are plotted against the number of $\mathrm{C}$ atoms for the networks with alkylene bridges or terminal alkyl groups in Figure 4. When considering the volume occupied by the electron clouds of the atoms in the networks, the addition of each $\mathrm{CH}_{2}$ segment is expected to yield a linear increase in He sample volume per Si atom. Changes in the volume of pores that are inaccessible to He are expected to cause deviations from linearity. The linear increase of He sample volume with increasing alkylene bridge length in Figure 4 indicates that the more densely packed BTMSH- and BTESO-derived networks did not contain larger volumes of He-excluding pores than the open BTESM- and BTESEderived networks. As for BMDESE-derived material, the addition of terminal methyl groups as compared to BTESE-derived material filled or blocked practically all ethylene-bridge-induced 
porosity. The accessible pore volumes obtained by vapor TG at room temperature varied from those obtained by $\mathrm{N}_{2}$ adsorption at $-196^{\circ} \mathrm{C}$ (Figure 2 ).

Information on the pore entrance sizes can be obtained by comparing the uptake of methanol, 1-propanol and cyclohexane in Figure 3. These molecules are at least partially hydrophobic and their uptake is therefore not expected to depend on pore chemistry; hydrophobic molecules can enter hydrophilic and hydrophobic channels with the same ease due to the lack of polar interaction. For TEOS-derived material the uptake of cyclohexane was approximately the same as the uptake of methanol and 1-propanol. This indicates that all probed micropores had entrance sizes larger than the minimum size of cyclohexane. Cyclohexane has a kinetic diameter $D_{\text {kin }}$ of $0.60 \mathrm{~nm}$ [27] but can pass pore entrances down to at least $0.42 \mathrm{~nm}$ [26]. Interestingly, for BTESM- and BTESE-derived networks the uptake of cyclohexane was significantly smaller than the uptake of methanol and 1-propanol; the incorporation of short organic spacers yielded smaller entrance sizes for part of the pores in the probed size range. The average pore entrance size cannot be deducted from these measurements as they provide only cut-off values, and it is possible that pore entrance expansion occurred on a larger scale than shrinkage. Also, the exclusion of cyclohexane in the materials with short or rigid bridges decreased with increasing spacer length in the order BTESM > BTESE > BTESB. Nevertheless, in the probed size range the incorporation of short organic bridges increased the dispersity in pore entrance sizes as compared to TEOS-derived material. This can be explained with the lower symmetry and mobility of methylene- and ethylene-bridged monomers. Their linear shape is expected to increase the intrinsic variation in micropore sizes and shapes as compared to the tetrahedral symmetry of TEOS-derived monomers. The lower mobility of BTESM- and BTESE-derived monomers during drying and consolidation, as discussed in the introduction, is expected to increase pore 
deformation in these stages of material processing. As for the networks with long and flexible organic bridges or terminal organic groups, only BTMSH- and PTMS-derived networks showed significant exclusion of cyclohexane as compared to the alcohol uptake. The small accessible pore volumes in BTESO- and MTMS-derived networks were equally accessible to cyclohexane and 1propanol.

Information on pore hydrophilicity can be obtained by comparing the uptake of water with that of the organic vapors. Water is not expected to cover non-polar surface areas (fill hydrophobic pores) because this reduces hydrogen bonding. However, water molecules are significantly smaller than methanol and can access all pores probed by methanol but also smaller ones. From this perspective it is surprising that the uptake of water did not exceed that of methanol for any of the networks, especially the one derived from TEOS. A possible explanation is that there were too few very small pores to cause a significant contribution to the total pore volume; the volume contribution of cylindrical pores increases cubically with their radius. An alternative explanation is that fully condensed, relatively hydrophobic surface areas in the pores of TEOS-derived material (and others) suppressed filling with water. Filling of very small pores would then compensate the non-filled parts of larger (hydrophobic) pores. In general, if water entered significant volumes of very small pores inaccessible to methanol, this would cause an underestimation of the hydrophobic character of the (organo)silica networks. Water/methanol uptake ratios $\alpha_{\text {water/methanol }}$ are listed in Table 1 to facilitate comparison.

The uptake of water increasingly stayed behind compared to the uptake of organic vapors in the order TEOS < BTESM < BTESE < BTMSH, corresponding with increasing hydrophobicity of the pore surfaces for longer alkylene bridge lengths. BTESO-derived material showed a methanol uptake equal to that of water and smaller than the uptake of 1-propanol and cyclohexane. This 
suggests that the uptake of water as well as methanol is suppressed by the hydrophobicity of the network. Swelling may have occurred for 1-propanol, but is not expected for cyclohexane due to its high vapor pressure. Values based on the uptake of 1-propanol in BTESO-derived material are therefore added in parentheses in Table 1. The lower relative uptake of water in MTMS-derived material as compared to BTESE-derived material, with the same C:Si ratio of 1 , indicated increasing surface hydrophobicity when switching from bridging to equivalent terminal groups. BTMSHderived material had a similarly low water uptake as PTMS-derived material with the same C:Si ratio of 3. This indicates that for such long organic segments their overall exposure does not depend on their configuration. The lower water uptake in MTMS-derived material with smaller organic groups as compared to PTMS-derived material can be explained by the reported lower hydroxyl concentration of the MTMS-derived material [5].

All in all, the incorporation of alkylene bridges of up to six $\mathrm{CH}_{2}$ units in silica networks increased the dispersity in pore entrance sizes in the probed size range. The porosity only exceeded that of inorganic silica for the incorporation of methylene and ethylene bridges. The incorporation of terminal alkyl groups yielded higher levels of porosity inaccessible to He as compared to alkylene-bridged networks with equivalent C:Si ratios. For low carbon concentrations the pore surface hydrophobicity increased with increasing alkylene bridge length or by switching from bridging to terminal groups.

\subsection{Surface area and pore entrance size}

PM measurements with $\mathrm{Ar}$ and $\mathrm{N}_{2}$ as probe gases were done to measure the uptake of molecules that are more polarizable than He and extract the surface-to-volume ratio and surface area of the samples. The distribution of added gas between outside and inside the sample framework 
(skeleton + pores) was calculated as described in our recent report introducing the method [26].

The amount of added gas inside the sample framework was converted to a change in concentration or 'apparent pressure' of probe molecules inside the accessible pore volume, $\Delta p_{\text {acc }}$. $\Delta p_{\text {acc }}$ was then divided by the pressure change outside the sample, $\Delta p_{c}$, to obtain a gas accumulation factor $\Delta p_{\text {acc }} / \Delta p_{\mathrm{c}}$. Note that $\Delta p_{\text {acc }}$ is only a measure for the number of probe molecules per unit pore volume and does not consider their physical state as free or adsorbed gas. The gas uptake inside the sample is assumed not to be limited by gas depletion outside the sample. The ratio of $\mathrm{N}_{2}$ accumulation over Ar accumulation, $\alpha_{\mathrm{N} 2 / \mathrm{Ar}}$, was calculated to assess the accessibility of pores to both gases. The previously reported relation between $\Delta p_{\text {acc }} / \Delta p_{\mathrm{c}}$ and the surface-to-volume ratio of zeolites [26] was used to determine the semi-quantitative surface-tovolume ratios $A_{\text {acc }} / V_{\text {acc }}$ of the (organo)silica materials. These surface-to-volume ratios provide information on the average pore size when assuming similar pore shapes. Multiplying $A_{\text {acc }} / V_{\text {acc }}$ with the accessible volume $V_{\text {acc }}$ as determined by vapor TG yields semi-quantitative surface areas $A_{\text {acc }}$. Results are listed in Table 2. Brunauer-Emmett-Teller (BET) surface areas $A_{\mathrm{BET}}$ as derived from conventional $\mathrm{CO}_{2}$ adsorption isotherms at $0{ }^{\circ} \mathrm{C}$ are added for comparison. Though PM cell pressure stabilization took longer for $\mathrm{Ar}$ and $\mathrm{N}_{2}$ than for $\mathrm{He}$, equilibrium was approached within the measurement time for all (organo)silicas.

The uptake of $\mathrm{Ar}$ and $\mathrm{N}_{2}$ is larger than the uptake of He for all samples except BMDESEderived material and this indicates adsorption of $\mathrm{Ar}$ and $\mathrm{N}_{2}$ on the pore surfaces. The highest absolute gas concentration inside the micropores was the equivalent of about 48 bar (Ar in BTESOderived material, $p_{\mathrm{c}} \approx 1.3 \mathrm{bar}$ ) and this corresponds with about $3 \%$ of the pore volume being occupied by $\mathrm{N}_{2}$ molecules. For such low gas concentrations no significant multilayer adsorption or curvature-related packing problems due to crowded monolayers are expected. As for the $\mathrm{N}_{2} / \mathrm{Ar}$ 
accumulation ratio, $\alpha_{\mathrm{N} 2 / \mathrm{Ar}}>1$ indicates hydrophilic pore surfaces because $\mathrm{N}_{2}$ is more sensitive to polar adsorption sites than $\operatorname{Ar}$ [26]. For all organosilica networks $\alpha_{\mathrm{N} 2 / \mathrm{Ar}}<1$, indicating that these materials contained a significant number of pores that were large enough to be entered by Ar but too small for $N_{2}$. The exclusion of $N_{2}$ increased with increasing alkylene bridge length and was the largest for terminal alkyl groups. These Ar-selective pores were not observed in TEOS-derived material, indicating that the incorporation of any organic group increased the dispersity in pore entrance sizes in the probed size range. This was also observed for most organosilica networks in the pore size range of the organic vapors as discussed above (Figure 3).

The trend in semi-quantitative surface areas of the (organo)silica materials roughly corresponds with the trend in porosity and spacer type; the surface area decreased in the order BTESM, BTESE, BTESB > TEOS > BTMSH, BTESO, MTMS, PTMS. This trend also follows from the BET surface areas derived from $\mathrm{CO}_{2}$ adsorption isotherms. Assuming similar pore shapes, including similar cavity/entrance size ratios, the increasing surface-to-volume ratios indicate decreasing average pore sizes in the order PTMS $>>\mathrm{BTMSH} \approx \mathrm{BTESM} \approx \mathrm{BTESE}>\mathrm{TEOS}>\mathrm{BTESB}>>\mathrm{MTMS}>$ BTESO. Apparently, the bulky organic groups in PTMS- and BTMSH-derived material that led to moderate or low porosity (Figure 3 and Table 1), did not reduce the average pore size. The smallest average pore sizes for MTMS- and BTESO-derived networks contrast with these materials showing no exclusion of cyclohexane over 1-propanol (Figure 3). Significant differences in pore shapes between these materials as compared to the networks with short and rigid bridges are plausible.

\subsection{Cavity size}


PM measurements with competitive gas filling were done to obtain more information on the micropore cavity dimensions. When filling a micropore structure with a single type of probe molecules, equilibrium can be reached without probe molecules needing to pass each other inside the pore structure and the filling rate is mostly determined at the pore entrances (bottlenecks). When a micropore structure is filled with gas $A$ and then filled further with another gas $B$, molecules of $A$ and $B$ have to pass each other inside the pores in order to mix and reach equilibrium. Since passing of molecules will occur mostly at the widest positions in the pores, the equilibration rate of gas B depends mostly on the cavity sizes and less on the size of the pore entrances. Comparing the equilibration behavior of gas B added to a background of gas $A$ with the equilibration behavior of gas $B$ added to a background of gas $B$ thus provides information specifically on the cavity size.

Figure 5a shows the filling progress in time after the addition of $\mathrm{N}_{2}$ to a background of either $\mathrm{N}_{2}$ or He for TEOS-, BTESM-, BTESE-, BTMSH-, BTESO-, BTESB- and MTMS-derived networks. Calculations were done as described in our recent report introducing the method [26]. For $\mathrm{N}_{2}$ being added to a background of $\mathrm{N}_{2}$ (solid curves) the cell pressure equilibrated slowest for MTMS-, BTMSH- and BTESO-derived networks, indicating somewhat smaller pore entrance sizes than for the other materials. For $\mathrm{N}_{2}$ being added to a background of He (dotted curves) the cell pressure equilibrated significantly slower for all networks, indicating that mixing of $\mathrm{N}_{2}$ and $\mathrm{He}$ inside the pore structures was hindered. The time until 30\% filling and the filling after $600 \mathrm{~s}$ (which are inversely related) are plotted in Figures $5 b$ and $5 c$, with the values for zeolites with known cavity sizes serving as semi-quantitative calibration points [26]. The precision of the results scales with the internal surface area of the sample; BMDESE- and PTMS-derived material could not be accurately analyzed. The results reflect only those pores that are accessible to $\mathrm{N}_{2}$, excluding the 
smallest micropores. The mesopores observed in TEOS- and BTESO-derived materials (Figure 2) are one or two orders of magnitude larger than the probe molecules and are thus expected to enable unhindered passing. Also, their contribution to the total uptake of $\mathrm{N}_{2}$ is relatively low because their surface-to-volume ratio is much smaller than for micropores. Therefore, the mesopores are not expected to influence the results in Figure 5 significantly. Variation in particle size of the powders is also not expected to influence the pore filling rates significantly. MTMSderived material yielded the finest powder as well as the slowest pore filling with $\mathrm{N}_{2}$ being added to a background of $\mathrm{N}_{2}$. Furthermore, even the largest solvent molecules showed rapid pore filling during vapor TG without discriminating between different samples.

The apparent cavity sizes increased in the order $\mathrm{BTESO} \approx \mathrm{MTMS}<\mathrm{BTMSH} \approx \mathrm{BTESB} \approx \mathrm{TEOS}$ $\approx$ BTESE < BTESM, roughly following the classification based on spacer type as discussed in the introduction. The equilibration rates for BTESO- and MTMS-derived material were similar to that of zeolites with a cavity size of $0.6 \mathrm{~nm}$. BTMSH-, BTESB-, TEOS- and BTESE-derived material showed equilibration rates similar to zeolites with a cavity size of $1.1 \mathrm{~nm}$. This does not correspond with reports on molecular dynamics simulation of inorganic and ethylene-bridged silica predicting only cavity sizes below $0.5-0.6 \mathrm{~nm}[11,24]$. However, the simulated networks were constructed by melting and quenching an inorganic silica crystal and thus have a very high packing density. The experimental PM results reflect sol-gel-derived networks including larger cavities due to imperfect packing and compaction. The theoretically predicted cavity expansion of about $0.05 \mathrm{~nm}$ from TEOS- to BTESE-derived networks [24] is within the error margin of the experimental PM technique.

\section{Conclusion}


The micropore structure of a series of organosilica materials with various organic groups in bridging and terminal positions was analyzed and compared to that of inorganic amorphous silica. The obtained pore volumes, semi-quantitative surface areas and semi-quantitative cavity sizes generally correspond with the known classification of 1) short or rigid organic bridges that open up the pore structure, 2) longer and more flexible bridges that cause pore filling and 3) terminal organic groups that reduce pore formation. However, phenylene-bridged material showed a lower porosity and smaller average pore size than ethylene-bridged material despite having more rigid and longer bridges; alignment of the phenylene rings probably counteracted their spacing effect. Also, the bulky terminal propyl and bridging hexylene groups did not appear to decrease the average pore size.

The general trend is observed that the incorporation of any organic group in the silica network increases the dispersity in micropore entrance sizes in the probed size range. While the pore structure of inorganic silica was equally accessible to all probe molecules, the incorporation of organic groups resulted in partial exclusion of cyclohexane over 1-propanol and partial exclusion of $\mathrm{N}_{2}$ over Ar. This can be explained with the lower symmetry and mobility of especially organically bridged silica monomers as compared to inorganic silica monomers, yielding more intrinsic as well as processing-related variations in micropore dimensions.

More refined micropore structure analyses may be achieved by using Ne as additional probe molecule for gas PM to fill the size gap between He and Ar. Ne is preferred over $\mathrm{H}_{2}$ because of its spherical shape and inertness; its high price is compensated by the small amount required per sample. As for organically bridged molecular sieving membranes, the large similarity between inorganic and organically bridged silica in terms of siloxane bond concentrations and (theoretical) micropore size distributions suggests that there is still room to improve their size-selective 
behavior. This may be done by adding post-treatments or re-optimizing the common synthesis and processing (drying) protocols. Alternatively, smaller pores may be obtained by using a mixture of short and longer alkylene bridges. The short bridges (i.e. methylene) can provide a rigid backbone with small pore openings, while the longer bridges (i.e. hexylene) partially fill up the micropore cavities and may enhance relaxation and compaction of the network.

\section{Acknowledgements}

Financial support from the Advanced Dutch Energy Materials (ADEM) program of the Dutch Ministry of Economic Affairs, Agriculture and Innovation is gratefully acknowledged. ADEM was not involved in the design, execution or publication of this research. Thanks to Cindy Huiskes and the Inorganic Membranes group of the University of Twente for providing the Autosorb equipment.

\section{Corresponding Author}

Corresponding author: j.e.tenelshof@utwente.nl

\section{Notes}

The authors declare no competing financial interest.

\section{References}


[1] G. Dubois, W. Volksen, T. Magbitang, R.D. Miller, D.M. Gage, R.H. Dauskardt, Adv. Mater. 19 (2007), 3989-3994.

[2] E.J. Kappert, D. Pavlenko, J. Malzbender, A. Nijmeijer, N.E. Benes, P.A. Tsai, Soft Matter 11 (2015) $882-888$.

[3] H.L. Castricum, A. Sah, M.C. Mittelmeijer-Hazeleger, C. Huiskes, J.E. ten Elshof, J. Mater. Chem. 17 (2007) 1509-1517.

[4] S.S. Latthe, H. Imai, V. Ganesan, A.V. Rao, Microporous Mesoporous Mater. 130 (2010) 115-121.

[5] A.P. Dral, C. Lievens, J.E. ten Elshof, Langmuir 33 (2017) 5527-5536.

[6] H.L. Castricum, A. Sah, R. Kreiter, D.H.A. Blank, J.F. Vente, J.E. ten Elshof, J. Mater. Chem. 18 (2008) $2150-2158$.

[7] H.L. Castricum, A. Sah, R. Kreiter, D.H.A. Blank, J.F. Vente, J.E. ten Elshof, Chem. Commun. (2008) 1103-1105.

[8] H.L. Castricum, R. Kreiter, H.M. van Veen, D.H.A. Blank, J.F. Vente, J.E. ten Elshof, J. Memb. Sci. 324 (2008) 111-118.

[9] M. Kanezashi, M. Kawano, T. Yoshioka, T. Tsuru, Ind. Eng. Chem. Res. 51 (2012) 944-953.

[10] K.S. Chang, T. Yoshioka, M. Kanezashi, T. Tsuru, K.-L. Tung, Chem. Commun. 46 (2010) 9140-9142.

[11] K.-S. Chang, T. Yoshioka, M. Kanezashi, T. Tsuru, K.-L. Tung, J. Memb. Sci. 381 (2011) 90-101.

[12] H.L. Castricum, G.G. Paradis, M.C. Mittelmeijer-Hazeleger, R. Kreiter, J.F. Vente, J.E. ten Elshof, Adv. Funct. Mater. 21 (2011) 2319-2329.

[13] H.W. Oviatt, K.J. Shea, J.H. Small, Chem. Mater. 5 (1993) 943-950. 
[14] R. Xu, M. Kanezashi, T. Yoshioka, T. Okuda, J. Ohshita, T. Tsuru, ACS Appl. Mater. Interfaces 5 (2013) 6147-6154.

[15] R. Xu, P. Lin, Q. Zhang, J. Zhong, T. Tsuru, Ind. Eng. Chem. Res. 55 (2016) 2183-2190.

[16] J.M. Rimsza, L. Deng, J. Du, J. Non. Cryst. Solids 431 (2016) 103-111.

[17] D.S. Wragg, R.E. Morris, A.W. Burton, Chem. Mater. 20 (2008) 1561-1570.

[18] K.J. Shea, D.A. Loy, Chem. Mater. 13 (2001) 3306-3319.

[19] X. Ren, K. Nishimoto, M. Kanezashi, H. Nagasawa, T. Yoshioka, T. Tsuru, Ind. Eng. Chem. Res. 53 (2014) 6113-6120.

[20] M. Kanezashi, Y. Yoneda, H. Nagasawa, T. Tsuru, K. Yamamoto, J. Ohshita, Am. Inst. Chem. Eng. J. 63 (2017) 4491-4498.

[21] L. Meng, M. Kanezashi, J. Wang, T. Tsuru, J. Memb. Sci. 496 (2015) 211-218.

[22] G. Li, M. Kanezashi, T. Tsuru, J. Memb. Sci. 379 (2011) 287-295.

[23] G.G. Paradis, D.P. Shanahan, R. Kreiter, H.M. van Veen, H.L. Castricum, A. Nijmeijer, J.F. Vente, J. Memb. Sci. 428 (2013) 157-162.

[24] T. Shimoyama, T. Yoshioka, H. Nagasawa, M. Kanezashi, T. Tsuru, Desalin. Water Treat. 51 (2013) $5248-5253$.

[25] A.P. Dral, K. Tempelman, E.J. Kappert, L. Winnubst, N.E. Benes, J.E. ten Elshof, J. Mater. Chem. A 5 (2017) 1268-1281.

[26] A.P. Dral, J.E. ten Elshof, Microporous Mesoporous Mater. 258 (2018) 197-204. 
[27] K. Akamatsu, S. Nakao, in: Handbook of advanced ceramics, $2^{\text {nd }}$ ed., Academic Press, Elsevier Ltd, Waltham, USA, 2013, p. 332. 


\section{Tables}

Table 1. Accessible pore volume $V_{\text {acc }}$ as derived from the methanol uptake during vapor TG, He density $\rho_{\text {He }}$ as derived from He PM, porosity $\Phi$ as derived from $V_{\text {acc }}$ and $\rho_{\mathrm{He}}$, and water/methanol uptake ratio

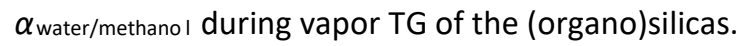

\begin{tabular}{lllllllllll}
\hline (organo)silica & & TEOS & BTESM & BTESE & BTMSH & BTESO & BTESB & BMDESE & MTMS & PTMS \\
\hline$V_{\text {acc }}$ & {$\left[\mathrm{cm}^{3} \mathrm{~g}^{-1}\right]$} & 0.13 & 0.21 & 0.19 & 0.09 & $0.01(0.04)^{\mathrm{b}}$ & 0.14 & 0.01 & 0.02 & 0.04 \\
& {$\left[\AA^{3} \mathrm{Si}^{-1}\right]^{\mathrm{a}}$} & 13 & 20 & 21 & 14 & $3(7)^{\mathrm{b}}$ & 21 & 1 & 3 & 7 \\
$\rho_{\text {He }}$ & {$\left[\mathrm{g} \mathrm{cm}^{-3}\right]$} & 2.0 & 1.8 & 1.6 & 1.3 & 1.2 & 1.5 & 1.2 & 1.3 & 1.1 \\
& {$\left[\AA^{3} \mathrm{Si}^{-1}\right]^{\mathrm{a}}$} & 49 & 55 & 71 & 119 & 151 & 97 & 106 & 85 & 148 \\
$\Phi$ & {$[\%]$} & 21 & 27 & 23 & 11 & $2(4)^{\mathrm{b}}$ & 18 & 1 & 3 & 4 \\
$\alpha_{\text {water/methanol }}$ & {$[-]$} & 0.97 & 0.94 & 0.60 & 0.30 & $0.73(0.27)^{\mathrm{b}}$ & 0.72 & 0.16 & 0.25 & 0.62 \\
\hline
\end{tabular}

a Volume per Si atom, calculated assuming $100 \%$ condensation.

${ }^{b}$ Value in parentheses is based on the uptake of 1-propanol instead of methanol.

Table 2. Gas accumulation factor $\Delta p_{\text {acc }} / \Delta p_{c}, N_{2} / A r$ accumulation ratio $\alpha_{\mathrm{N} 2 / A r}$, semi-quantitative surface-tovolume ratio $A_{\text {acc }} / V_{\text {acc }}$ and semi-quantitative surface area $A_{\text {acc }}$ of the (organo)silicas as derived from He, Ar and $\mathrm{N}_{2}$ PM. BET surface area $A_{\text {BET }}$ of the (organo)silicas as derived from $\mathrm{CO}_{2}$ adsorption isotherms at $0{ }^{\circ} \mathrm{C}$.

\begin{tabular}{|c|c|c|c|c|c|c|c|c|c|c|}
\hline (organo)silica & & TEOS & BTESM & BTESE & BTMSH & BTESO & BTESB & BMDESE & MTMS & PTMS \\
\hline \multirow[t]{3}{*}{$\Delta p_{\text {acc }} / \Delta p_{\mathrm{c}}[-]$} & $\mathrm{He}$ & 1.0 & 1.0 & 1.0 & 1.0 & $1.0(1.0)^{a}$ & 1.0 & 1.0 & 1.0 & 1.0 \\
\hline & $\mathrm{Ar}$ & 8.6 & 7.7 & 7.9 & 7.4 & $37(14)^{\mathrm{a}}$ & 11 & 3.0 & 21 & 3.5 \\
\hline & $\mathrm{N}_{2}$ & 8.6 & 7.3 & 7.2 & 5.7 & $26(10)^{\mathrm{a}}$ & 9.9 & 0.0 & 12 & 1.1 \\
\hline$\alpha_{\mathrm{N} 2 / \operatorname{Ar}}[-]$ & & 1.00 & 0.94 & 0.91 & 0.78 & 0.70 & 0.92 & n.a. & 0.61 & 0.30 \\
\hline
\end{tabular}




\begin{tabular}{|c|c|c|c|c|c|c|c|c|c|}
\hline$A_{\mathrm{acc}} / V_{\mathrm{acc}}\left[\mathrm{m}^{2} \mathrm{~cm}^{-3}\right]$ & 6369 & 5864 & 5953 & 5667 & $22067(9515)^{a}$ & 7542 & 3257 & 12964 & 3515 \\
\hline$A_{\mathrm{acc}}\left[\mathrm{m}^{2} \mathrm{~g}^{-1}\right]$ & 832 & 1205 & 1148 & 514 & $310(361)^{a}$ & 1076 & 29 & 323 & 154 \\
\hline$A_{\text {вет }}\left[\mathrm{m}^{2} \mathrm{~g}^{-1}\right]$ & 300 & 495 & 415 & 166 & 139 & 371 & n.d. & 169 & 83 \\
\hline
\end{tabular}




\section{Figure captions}

Figure 1. Chemical structures and abbreviations of the used (organo)silica precursors.

Figure 2. $\mathrm{N}_{2}$ adsorption isotherms at $-196^{\circ} \mathrm{C}$ for TEOS-, BTESM-, BTESE-, BTMSH-, BTESO-, BTESB-, MTMS- and PTMS-derived materials.

Figure 3. Vapor uptake in the (organo)silicas as measured with TG during exposure to a flow of $\mathrm{N}_{2}$ with a vapor. The uptake was averaged between 6 and $18 \mathrm{~h}$ filling time and the error bars indicate two times the standard deviation.

Figure 4. He sample volume plotted against the number of $C$ atoms for organosilicas with bridging alkylene or terminal alkyl groups as measured with He PM.

Figure 5. a) Pore filling curves for $\mathrm{N}_{2}$ added to a background of $\mathrm{N}_{2}$ (solid curves) and for $\mathrm{N}_{2}$ added to a background of He (dotted curves) for TEOS-, BTESM-, BTESE-, BTMSH-, BTESO-, BTESB- and MTMS-derived networks. b) Time at $30 \%$ filling of $\mathrm{N}_{2}$ added to a background of He. The semiquantitative calibration data was obtained from a series of zeolites. ${ }^{26} \mathrm{c}$ ) Degree of filling at $t=600 \mathrm{~s}$ for $\mathrm{N}_{2}$ added to a background of $\mathrm{He}$. The semi-quantitative calibration data was obtained from a series of zeolites. ${ }^{26}$

${ }^{\text {a }}$ For BTESO-derived material the crosses are based on the accessible pore volume from the uptake of 1-propanol instead of methanol. 


\section{Figures}

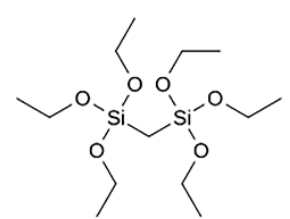

bis(triethoxysilyl)methane (BTESM)

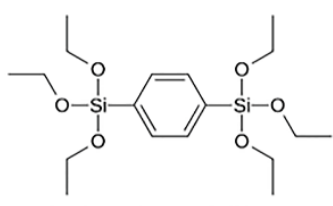

1,4-bis(triethoxysilyl)benzene (BTESB)

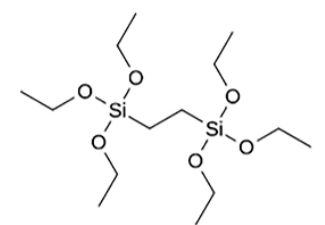

1,2-bis(triethoxysilyl)ethane (BTESE)

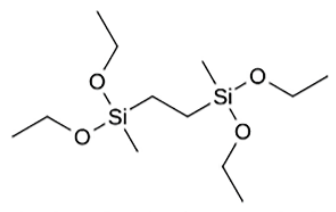

1,2-bis(methyldiethoxysilyl)ethane (BMDESE)

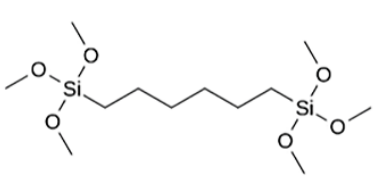

1,6-bis(trimethoxysilyl)hexane (BTMSH)

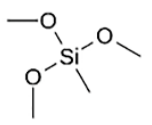

methyltrimethoxysilane (MTMS)

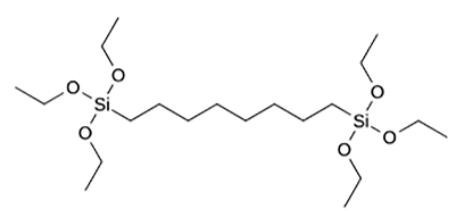

1,8-bis(triethoxysilyl)octane (BTESO)

Figure 1.

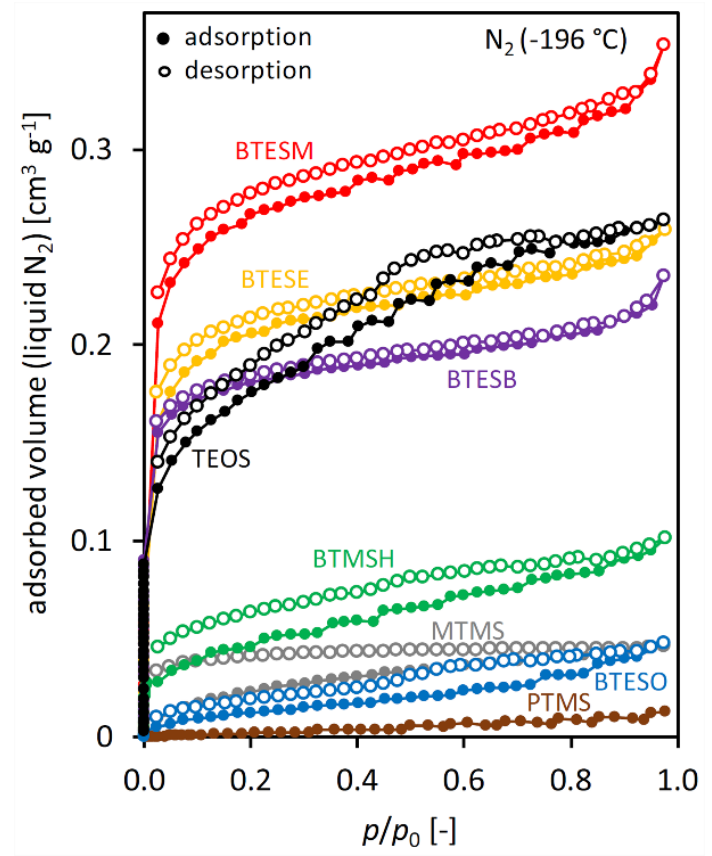

Figure 2. 


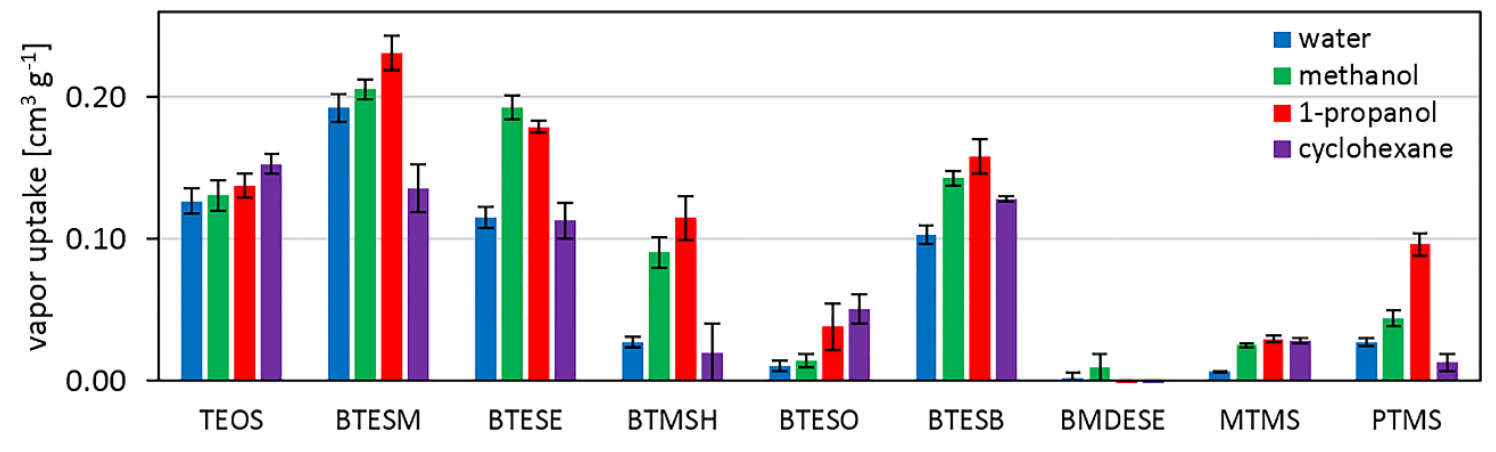

Figure 3.

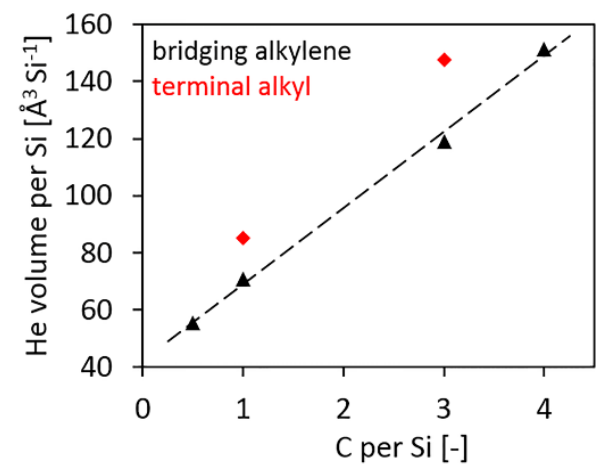

Figure 4. 

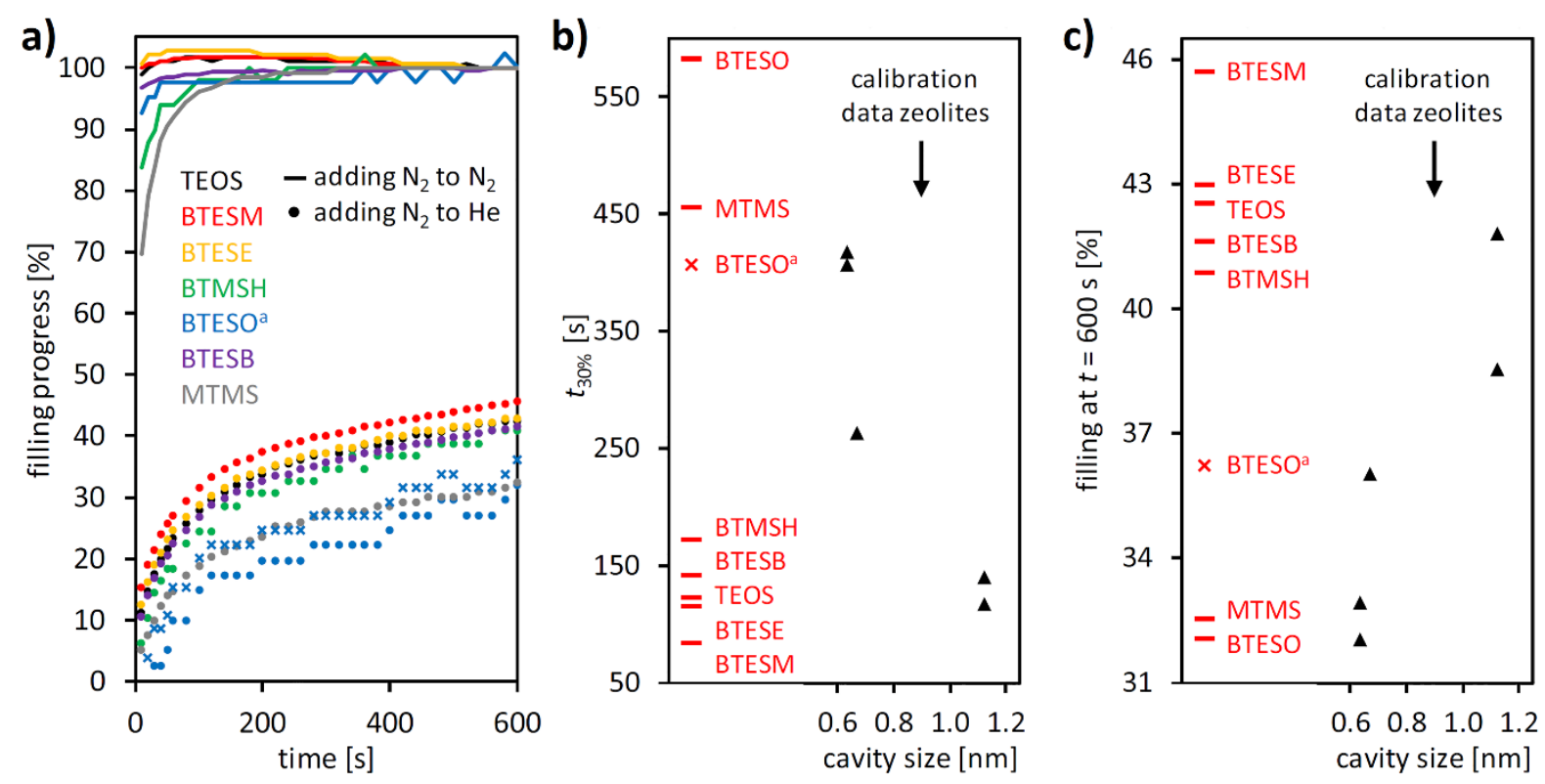

Figure 5. 